\title{
Territorialidades sônicas e re-significação de espaços do Rio de Janeiro
}

\author{
Sonic Territoriality and re-meaning \\ of the spaces of Rio de Janeiro
}

\begin{abstract}
Micael Herschmann I micaelmh@globo.com
Doutor em Comunicação pela UFRJ, pesquisador do CNPq, professor do Programa de PósGraduação em Comunicação da UFRJ, onde também dirige o Núcleo de Estudos e Projetos em Comunicação. Autor dos seguintes livros individuais: Indústria da música em transição (Ed. Estação das Letras e das Cores, 2010); Lapa, cidade da música (Ed. Mauad X, 2007); O funk e o hip-hop invadem a cena (Ed. UFRJ, 2000)..
\end{abstract}

Cíntia Sanmartin Fernandes I Cintia@LagoadaConceicao.com Doutora em Sociologia Política pela Universidade Federal de Santa Catarina (UFSC) com Doutorado Sanduíche junto à Université René Descartes-Paris V/Sorbonne. Pós-doutora em Comunicação pela UFRJ e em Comunicação e Semiótica pela PUC-SP. É professora visitante da Faculdade de Comunicação Social e do Programa de Pós-Graduação em Comunicação da UERJ. Autora do livro individual: Sociabilidade, Comunicação e Política: a experiência estéticocomunicativa da Rede MIAC na cidade de Salvador (Ed. E-Papers, 2009)..

\section{Resumo}

Neste artigo avalia-se a relevância das experiências, dos afetos e da arquitetura dos lugares na alteraçáo das territorialidades e do cotidiano urbano: parte-se do pressuposto de que estes fatores potencializam diversas sociabilidades fundantes de um novo ethos (modos de co-habitar). Analisa-se de forma preliminar o papel de algumas atividades musicais na re-significaçáo dos espaços no Centro da cidade do Rio de Janeiro. Buscou-se neste artigo descrever analiticamente a dinâmica de quatro grupos musicais - Samba da Ouvidor, Roda de Choro Antigamente, Nova Lapa Jazz e Monte Alegre Hot Jazz Band - que se organizam através das redes sociais, promovem dinâmicas colaborativas e são capazes de mobilizar segmento expressivo da população da cidade (incentivando a "ocupaçăo da cidade", mesmo de áreas degradadas e consideradas de "risco"), alavancando no seu entorno um conjunto de atividades e iniciativas econômicas, sociais e culturais, antes praticamente inexistentes. Palavras-Chave: Comunicação; Música; Cidade; Sociabilidade.

\begin{abstract}
In this article is valued the relationship of the experiences, of the affection and of the architecture of the places producing the alteration of the territorialities and of the daily urban one: we are working with the hypothesis that these factors powerful the socius, are funding a new ethos. This work analyzes the role of some musical activities (in a preliminary way) in the process of re-meaning of the spaces in the Center of Rio de Janeiro. The dynamics of four musical groups - Samba do Ouvidor, Roda de Choro Antigamente, Nova Lapa Jazz and Monte Alegre Hot Jazz Band - are focused here. These groups are organized through the social nets, promote collaborative dynamics and are capable to mobilize expressive segments of the population of the city (to motivate the "occupation of the city", even of degraded, considered "risky" areas), fomented indirectly, in some way, economic, social and cultural activities, before practically inexistent.
\end{abstract}

Keywords: Brazil-Portugal relations; Brazilian music; Globalization. 


\section{Introdução}

Após um longo período de decadência socioeconômica, política e cultural (iniciado com a transferência da capital federal para Brasília) - que durou até a segunda metade dos anos de 1990 -, a Cidade do Rio de Janeiro vem recuperando nos últimos quinze anos um lugar de protagonismo no cenário nacional, especialmente no âmbito cultural.

Parte-se do pressuposto de que, se por um lado, os investimentos públicos e privados que vêm sendo direcionados à cidade por conta da realização de megaeventos (nacionais e internacionais) esportivos e de entretenimento (tais como: os Jogos Pan-Americanos, a Copa das Confederaçóes, a Copa do Mundo, o Rock in Rio, a Olimpíada, entre outros) têm um significativo papel para a reversão deste quadro; por outro lado, as atividades musicais vêm também desempenhando um relevante papel na re-significação da urbe, tal como pode ser constatado pelo crescente êxito de algumas áreas do Centro - como Lapa e Praça XV - que passaram nos últimos anos a gravitar em torno das atividades musicais e gastronômicas.

Estas áreas - que estavam anteriormente degradadas e ofereciam riscos à segurança pública - hoje abrigam dois Pólos Históricos, Gastronômicos e Culturais estratégicos do Rio: o da Lapa (que tem como eixo as ruas Mem de Sá e Lavradio e é um território também conhecido como Pólo do Rio Antigo, por contemplar áreas da Cinelândia e da Praça Tiradentes) e o da Praça XV (que tem como eixo central o cruzamento das ruas do Ouvidor e do Mercado). A consolidação destes pólos é o resultado de atuaçôes e iniciativas de diversos atores sociais que se apropriaram e re-significaram política, afetivamente e simbolicamente estes espaços da cidade.

Tanto o Pólo da Lapa como o da Praça XV se destacam como casos exemplares - de grande sucesso econômico (dinamizando expressivamente o comércio local) - que atraem grande visitação e hoje reúnem amplo número de atividades culturais e turísticas que são estratégicos para a cidade (FERNANDES, 2011; HERSCHMANN, 2007).

Ao mesmo tempo, na última década, surgem práticas espontâneas "engajadas", formas de "ativismo musical" ou de "comunidades sônicas" (HERSCHMANN, 2011, OBICI, 2010) - não necessariamente organizadas por profissionais do mainstream ou do chamado setor independente da música - que dinamizam e re-potencializam a sociabilidade desses territórios estratégicos do Centro do Rio de Janeiro, os quais correm os riscos, ciclicamente, de "desvitalizar-se", como sugere a história desta cidade.

Desse modo, o objetivo deste artigo é analisar - ainda que de forma preliminar (dado o momento da pesquisa que está sendo realizada) - o papel de algumas atividades musicais na re-significaçáo de espaços do Rio, buscando reunir informações que permitirão, num segundo momento (da investigação em curso), construir um "mapa sensível" ou mais especificamente uma espécie de esboço de um "arquipélago" (MARTÍN-BARBERO, 2004) sônico da cidade. 


\section{Um olhar que privilegia a rua e o cotidiano da cidade}

Antes de analisar a dinâmica dos grupos que vêm sendo estudados, vale ressaltar alguns aspectos fundamentais para se compreender a dinâmica da vida contemporânea nas grandes cidades.

As principais transformaçóes acarretadas pela globalização situam-se tanto no âmbito da organização econômica, como das relaçóes sociais, dos padrôes de vida e cultura, das transformaçóes do Estado e da política. Conforme Ianni (2003), o mundo foi se transformando em território onde tudo - gente, coisas e ideias - se desterritorializa e se reterritorializa, adquirindo novas modalidades de territorialização.

Assim a cidade tece o seu imaginário de forma aberta e multiforme não podendo ser engessada, pois se renova constantemente através do jogo cotidiano entre centramento-descentramento, territorialização-(des)territorialização-(re)territorialização, fronteiras fixas-movediças, nas quais as diversas "neotribos" (MAFFESOLI, 1987) tecem os significados dos lugares onde estabelecem seus intercâmbios culturais. Essa dinâmica é retro-alimentada pelas relaçóes entre o local e o global que se interpenetram tornando-se inseparáveis.

A cidade do Rio de Janeiro, reconhecida como uma cidade global é representativa dessas relaçóes em que os espaços são redefinidos seguindo os fluxos e os fixos, as continuidades e as descontinuidades cotidianas balizadas por modos de estar, de vivenciar, de experienciar os locais e lugares por meio de uma prática cultural glocal (ROBERTSON, 2002). Essa prática, representativa das "artes do fazer" cotidiano (DE CERTEAU, 1994) pode ser apreendida em diversos "pedaços" da cidade. Cidade que aqui é tratada como espaço relacional, vivo, dinâmico, constituído por interaçóes socioculturais-ambientais que em movimento enunciam diversos modos de usos e práticas sociais.

No campo da sociologia e da comunicação os estudos sobre as políticas públicas das cidades centram-se em análises que consideram os indicadores produzidos pelas instituiçóes públicas como fonte principal dos estudos sobre as dinâmicas socioculturais das metrópoles, tendo como principal indicador o acesso aos pontos de cultura das cidades. Criam desse modo mapas sociopolíticos culturais com bases nos circuitos programáticos da cidade.

O que propomos é uma análise, que não desconsidera os indicadores políticos públicos, mas que se alicerça nas práticas vividas do e no cotidiano. Entender como, e de que modo (modus vivendi), os indivíduos e grupos se relacionam e ocupam a cidade de um modo não programático, mas se ajustando aos espaços e aos diversos grupos culturais que nele os re-significam. Desse modo, elevamos o cotidiano, as interaçóes socioculturais nele praticadas como o impulso primeiro para se refletir as dinâmicas do espaço social das cidades.

Implica, portanto, exercitar uma prática compreensiva que parte do fenômeno para explicar a sociabilidade contemporânea. Uma compreensão que considere a complexidade, a mutabilidade constante das conformaçóes sócio-espaciais-corporais, em que a separação tempo/espaço, sujeito/objeto, natureza/cultura seja posta "em suspensão" no entendimento máximo de que são os homens (corpo e 
espírito) em movimento na/pela cidade, na experiência sensível de seu contato e interação social que nela têm lugar, os quais constroem os sentidos sócio-espaciais, que geram as espacialidades no âmbito que as define (SENNETT, 1987) ${ }^{1}$.

Concentram-se as "formas de olhar" para as territorialidades: em uma perspectiva teórica e metodológica que considera a sensibilidade, os laços sociais fluidos, a deriva, a errância e o nomadismo de valores característicos das atuais dinâmicas societais (MAFFESOLI, 2001).

Propóe-se, deste modo, compreender a cidade do Rio de Janeiro e suas práticas culturais a partir de uma perspectiva intercultural (CANCLINI, 2011) e, assim, adentrar o universo das redes que tecem o cotidiano da cidade. Parte-se do pressuposto de que estas redes permitiriam construir uma cartografia que se delineia nos espaços, os quais colocam em evidência a diversidade cultural "formante" das urbes, ou seja, as suas múltiplas "territorialidades" (HAESBAERT, 2001).

Nesse sentido, considera-se a rua - e não os mapas que enunciam os projetos urbanísticos - como sendo o espaço no qual se pode compreender a "alma" da cidade (RIO, 1908): a cidade imaginária, sentida e compartilhada em que realizamos nossas experiências cotidianas, das mais banais às mais complexas e que constroem os sentidos dos diferentes lugares.

\section{Ativismo musical na cidade do Rio}

Como foi ressaltado anteriormente, a partir de um estudo preliminar realizado na cidade do Rio de Janeiro, foram selecionados e estáo sendo pesquisados quatro grupos musicais - e seus respectivos fãs -, os quais vêm construindo relevantes agrupamentos na urbe: que praticam este ativismo musical, o qual vem permitindo re-significar algumas áreas que - apesar do momento de apogeu atual - são ciclicamente abandonadas e/ou que historicamente, com alguma regularidade, fizeram parte de uma "geografia do medo" da cidade.

\section{- Grupos do Samba da Ouvidor e a Roda de Choro Antigamente que atuam no Pólo da Praça XV}

Chama a atenção o fato de que desde 2004 a localidade começou a construir patamares expressivos de sustentabilidade por iniciativa de artistas, empresários e alguns fãs.

Considerada sempre como uma área com potencial de crescimento pelo fato de estar cercada de importantes equipamentos culturais e históricos do Rio - isto é, um lugar localizado em um quadrilátero de museus importantes da cidade (tais como o Paço Imperial, Centro Cultural Banco do Brasil e Casa França-Brasil) - o fato é que a área encontrava-se estagnada, especialmente depois da migração dos negócios no mercado financeiro da Bolsa de Valores do Rio de Janeiro para a de São Paulo.

Se antes eram menos de dez bares e restaurantes nesse território, hoje são aproximadamente 40 estabelecimentos - entre bares, restaurantes, livrarias, museus, galerias de arte, casa de shows eróticos e uma cooperativa de artistas autônomos (associados a um dos blocos de carnaval mais prestigiados da 
cidade, o Boitatá) -, o que representa um crescimento de 200\% nas atividades de economia da cultura. Segundo estimativas dadas pelos atores entrevistados, poder-se-ia afirmar que cerca de 40 mil pessoas frequentam este pólo por mês, gastando em média 40 reais, gerando um circuito da economia da música e do entretenimento (que reúne atividades de gastronomia, turismo e artes visuais) que arrecada mensalmente mais de dois milhóes de reais. Vale ressaltar também que um número expressivo das atividades culturais e de entretenimento gira em torno da música, de certa maneira pode-se afirmar que se organizou um circuito (não de forma exclusiva) de samba e choro nesta localidade.

Como ressalta Rodrigo Ferrari (dono da livraria Folhas Secas), um dos principais articuladores iniciais deste ativismo musical, desde dezembro de 2006 intercalam-se nesta localidade, nas tardes de terça-feira, a cada 15 dias, o Samba da Ouvidor e o grupo de choro Antigamente. Essa iniciativa espontânea reúne os admiradores do samba, que além de compartilhar a música, desfrutam ainda de toda a cultura gastronômica relacionada a este universo cultural. A participação do Antigamente ampliou o espectro das possibilidades de consolidação da rua do Ouvidor como mais um espaço para o culto do samba e do chorinho no Rio de Janeiro, despertando o interesse tanto do poder local como dos meios de comunicação associados aos negócios turísticos.

$\mathrm{Na}$ realidade, analisando estas duas comunidades sônicas que atuam ali, é possível observar que há um vínculo forte e muito importante entre os músicos e o público. Constrói-se uma espécie de economia solidária que envolve artistas, fấs e frequentadores da localidade. Não só se realiza sistematicamente a prática do "passar o chapéu", mas também se compram discos e acessórios ligados a esses artistas, bem como se acompanha o trabalho e a trajetória desses grupos nas redes sociais da web.

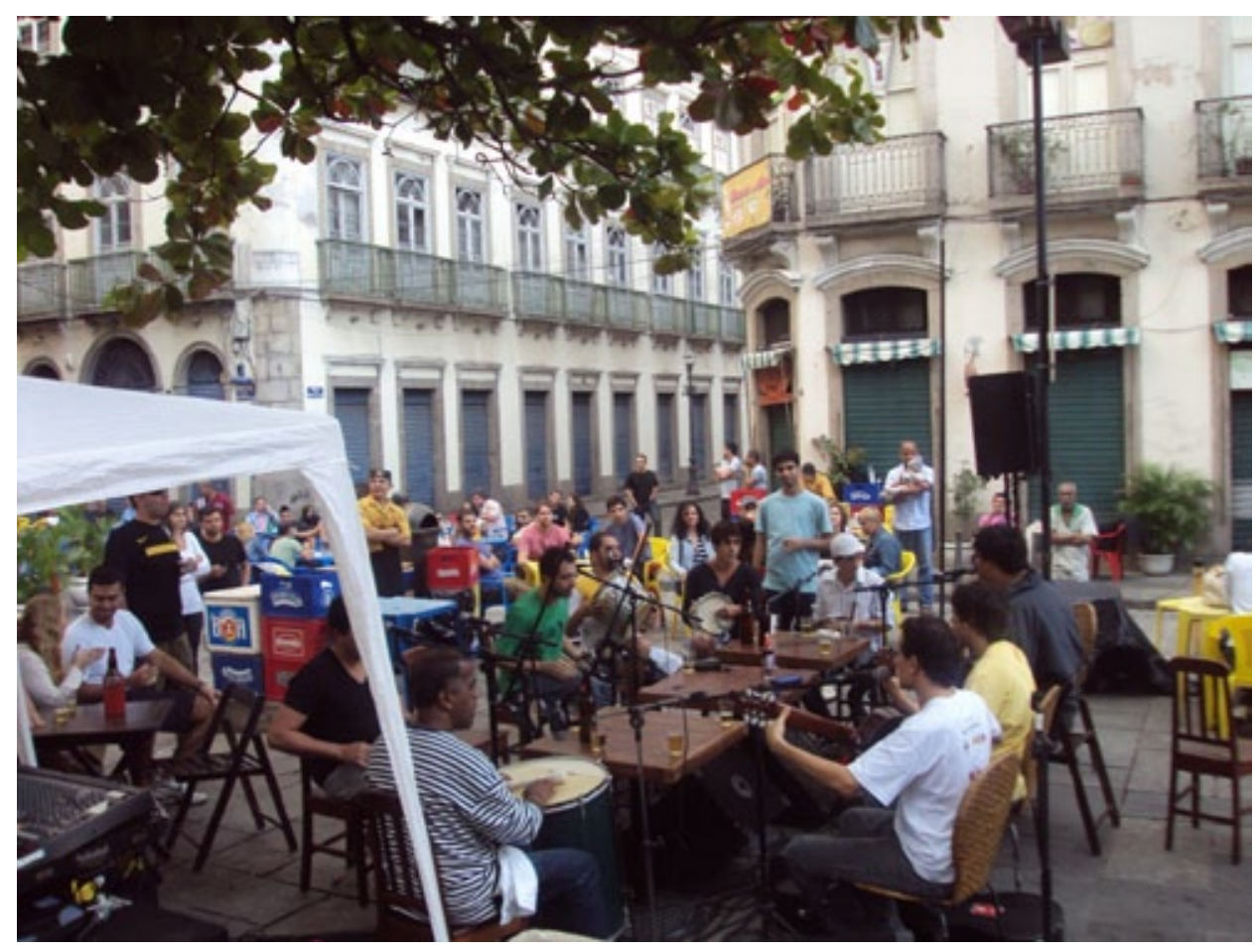

Foto 1: Samba da Ouvidor, 2011. Fonte: Acervo pessoal Cíntia S. Fernandes 


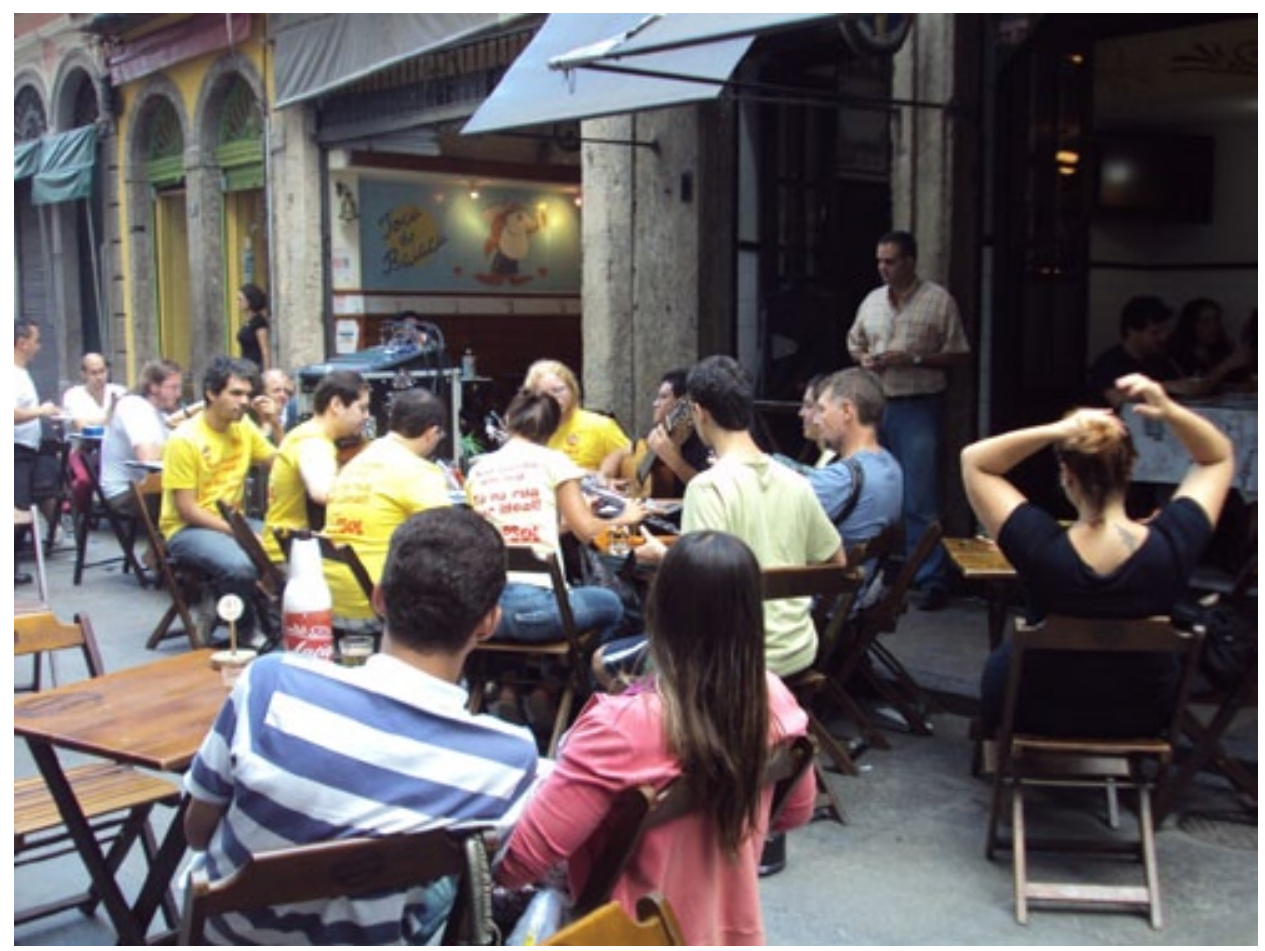

Foto 2: Roda Choro Antigamente, 2011. Fonte: Acervo pessoal Cíntia S. Fernandes

Evidentemente, hoje o Estado apóia as iniciativas formais e informais desenvolvidas nesta localidade. Assim, inspirado no crescimento alcançado pelo circuito do samba e choro na Lapa e buscando tentativa de dinamizar o projeto de revitalização que se iniciou na segunda metade dos anos 1990 no Centro do Rio de Janeiro (HERSCHMANN, 2007), a Prefeitura do Rio, em conjunto com Sebrae-RJ, SindRio, Senac-Rio e Associação Comercial do Rio de Janeiro, percebendo a mobilização de inúmeros atores sociais que começaram a investir ali, promoveu - no fim da primeira década do século XXI - as cercanias da Praça $\mathrm{XV}$ ao patamar de "ponto de efervescência turística e cultural da cidade", isto é, à condição de "Pólo Histórico, Cultural e Gastronômico".

- Grupos Nova Lapa Jazz e Monte Alegre Hot Jazz Brasil, que atuam no Pólo do Rio Antigo (ou da Lapa) e nos seus arredores

A Lapa é uma região do Centro do Rio de Janeiro identificada com a música - especialmente com o samba e choro - e que, a despeito da crise da grande indústria fonográfica (HERSCHMANN, 2010; YÚDICE, 2007), vem obtendo um êxito expressivo.

É possível constatar que se construiu nessa localidade um nicho de mercado de grande vitalidade, embora à margem da grande indústria da música. Na realidade, a Lapa vem se constituindo nos últimos anos, diferentemente de outros importantes centros que aglutinaram atividades associadas à música brasileira do país, pela vontade e iniciativa dos atores sociais, isto é, a partir da articulação espontânea dos empresários, artistas e lideranças locais. Diferentemente de outras localidades do país em que se produziu sustentabilidade a partir da atividade da música, o sucesso dessa microrregião 
foi alcançado - num primeiro momento - sem uma participação mais efetiva do Estado, a partir da articulação espontânea dos empresários locais que gravitam em torno da Associação Comercial do Centro do Rio Antigo e de lideranças importantes (HERSCHMANN, 2007).

É importante destacar a situação em que se encontrava a Lapa até bem pouco tempo: localizada no centro histórico mais importante da cidade do Rio, este território, apesar de todo seu passado relacionado com a música, vivia desde a década de 1980 uma situação de decadência e estagnação. Só a partir de meados dos anos 1990 - com as rodas e, posteriormente, com os concertos ao vivo de samba e choro -, por iniciativa de lideranças como Lefê de Almeida, Carlos Thiago Alvim, Plínio Froes e Angela Leal (articulados a inúmeros artistas e produtores culturais de samba e choro, tais como Teresa Cristina, Henrique Cazes, Mauricio Carrilho, entre outros), é que voltaram a se destacar ali as casas de espetáculo (que investem nestes gêneros musicais) e, com elas, foi retornando o interesse do público (HERSCHMANN, 2007).

Segundo dados de um levantamento realizado em meados da década passada, há ali mais de 120 estabelecimentos do setor do entretenimento, que vêm atraindo em média 500 mil pessoas, gerando uma economia de aproximadamente 17 milhôes de reais, por mês. Neste levantamento das atividades que são desenvolvidas na regiáo, pode-se constatar que quase 50\% dos estabelecimentos estáo no ramo de bares e restaurantes e que possuem uma segunda atividade ligada à música. Este dado confirma que boa parte da economia da regiáo gira em torno das casas de espetáculo e a maior parte delas foi inaugurada nesse novo círculo virtuoso da localidade. Aliás, segundo algumas estimativas, vem ocorrendo na região nos últimos anos - em função do sucesso da região - um crescimento do número de empregos da ordem de 20\% (HERSCHMANN, 2007).

Apesar do grande êxito, mesmo certas zonas nas adjacências deste pólo não foram completamente revitalizadas pelo Pólo do Rio Antigo (ou da Lapa). Ou seja, os interesses do dos empresários locais e a ação do Estado não re-significou completamente algumas parte da periferia do pólo. Assim, nos locais em que a lógica mercantil ou instrumental do Estado não tem sido efetiva, o ativismo musical (a lógica sensível) tem se feito presente de forma fundamental. Inclusive, vários frequentadores entrevistados no levantamento preliminar realizado afirmam que localidades como a da Rua Monte Alegre e a Praça Tiradentes, especialmente após o horário do happy hour ou à noite, são áreas em que - até bem pouco tempo atrás - temiam circular. Referem-se ao contexto atual em que se instalam temporariamente ali respectivamente os grupos musicais de jazz - no caso o Monte Alegre Hot Jazz Brasil e o Nova Lapa Jazz - como um momento importante de "re-ocupação" e ampliação do "direito a cidade". 


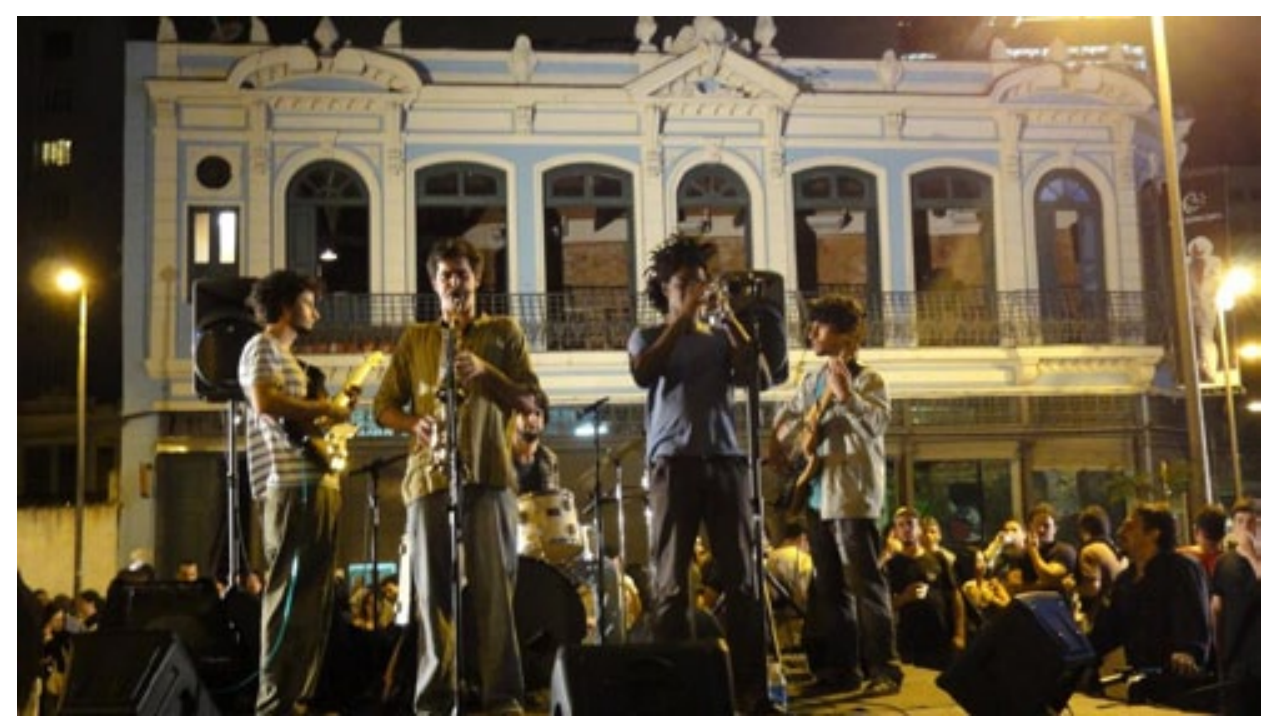

Foto 3: Nova Lapa Jazz Fonte: Acervo pessoal Cíntia S. Fernandes

Cabe sublinhar ainda que, nos últimos dois anos, é possível encontrar inúmeras referências nos blogs, nas redes sociais (Orkut, Facebook etc.) e até na mídia tradicional (impressa e audiovisual) às inúmeras atividades que vêm sendo desenvolvidas por estes grupos musicais no Rio de Janeiro. No trabalho de campo realizado junto aos frequentadores destas rodas foi possível atestar a crescente importância da "musicabilidade" (FERNANDES, 2011) no cotidiano dos cariocas. A demanda social por concertos de jazz, choro e samba é tão expressiva que cada vez mais é possível identificar a presença destes gêneros musicais nos eventos públicos organizados com o apoio do Estado na cidade do Rio.

Maffesoli - no livro O ritmo da vida - identifica uma centralidade da "experiência" na sociedade contemporânea. O autor ressalta o quanto esta é relevante para compreender as mobilizaçóes e engajamentos sociais hoje:

[...] a experiência é a palavra-chave para explicar a relaçâo que cada um estabelece com o grupo, a natureza, a vida em geral. Experiência que ignora escrúpulos racionais, repousando essencialmente no aspecto nebuloso do afeto, da emoção, da sintonia com o outro. É precisamente por estar a vibração na ordem do dia que convém adotar uma postura intelectual que saiba dar conta dela. [...] O lugar central da experiência exprime-se através desse resvalar que vai da História geral e segura de si às pequenas histórias que constituem o cimento essencial das tribos urbanas. Com isto, o discurso doutrinário dá lugar à vibração comum e ao sentimento de pertencimento que isto fatalmente induz (MAFFESOLI, 2007, p. 203-205).

Herschmann - na sua análise do crescimento do interesse pelos concertos ao vivo para a indústria da cultura e da música - ressalta que o público: se, por um lado, não está disposto a pagar pela maioria dos fonogramas consumidos (especialmente no ambiente digital); por outro lado, valoriza crescentemente os concertos ao vivo, as "afetividades" e estesias que são geradas nos mesmos, ou melhor, os consumidores/fãs de música que gravitam em torno de artistas e gêneros musicais estão dispostos a pagar valores, mesmo que elevados, por uma experiência aprazível e memorável (HERSCHMANN, 2010). 
Maffesoli segue oferecendo também algumas pistas interessantes. Em seu livro intitulado $O$ tempo das tribos, sugere ver os grupos sociais na sociedade atual como uma espécie de "neotribos", como comunidades fundadas na "emoção": "[...] a comunidade emocional é instável, aberta, o que pode torná-la, sob muitos aspectos, anômica com relação à moral estabelecida (MAFFESOLI, 1987, p. 22) 2 .

Assim, tendo em vista o que já foi assinalado até aqui neste trabalho, poder-se-ia deduzir por que os encontros presenciais promovidos pela música ao vivo são tão relevantes para a re-significação dos espaços urbanos. Mais do que isso: pode-se começar a compreender não só as razões de estas iniciativas de ativismo musical estarem ocupando um "lugar" significativo hoje na dinamização das culturas urbanas, mas também por que se apresentariam hoje como uma "alternativa", a qual viabilizaria em alguma medida a visibilidade e a continuidade de práticas e rotinas de amadores e (semi)profissionais da música em uma época marcada pelas incertezas (pelo sentimento de "crise") e pela "reestruturação da indústria da música" (HERSCHMANN, 2010).

Segundo Maffesoli, essas reunióes presenciais permitiriam (re)atualizar o sentimento de comunidade:

\begin{abstract}
A experiência com o outro fundamenta a comunidade, mesmo que ela seja conflitual. A fusão da comunidade pode ser perfeitamente des-individualizante. Ela cria uma união em pontilhado que náo significa uma presença plena no outro (o que remete ao politico), mas antes estabelece uma relação oca que chamarei de relação táctil: na massa a gente se cruza, se roça, se toca, interaçôes se estabelecem, cristalizaçôes se operam e grupos se formam. Estas relaçóes tácteis [presenciais], entretanto, através de sedimentaçôes sucessivas, não deixam de criar uma ambiência especial: exatamente o que chamei de uniāo pontilhado [...]: as redes sexuais, as diversas formas de solidariedade, os encontros esportivos e musicais [tais como concertos, festivais] são todos indicios de um ethos em formação. É isto que delimita esse novo espirito de tempo que podemos chamar de socialidade (MAFFESOLI, 1987, p. 102-103).
\end{abstract}

Assim, poder-se-ia repensar a articulação entre experiências presenciais e não presenciais, tácteis e não tácteis, sem depreciar aquelas que ocorrem em geral a distância (bastante presentes na internet e de modo geral no cotidiano hoje). Contudo, é importante sublinhar a relevância das trocas diretas para a atualização do grupo e do sentimento de coletividade. Os encontros musicais presenciais - tais como as rodas de choro, samba e (por que não?) de jazz, que são realizadas com regularidade por estes grupos musicais nas ruas e praças do Centro do Rio de Janeiro -, portanto, seriam muito relevantes, pois colocariam o grupo em "epifania", criando condiçôes para a emergência de "afetividades", processos intensos de identificação e interação (SODRÉ, 2006; FERNANDES, 2009), que legitimariam o grupo. Neste sentido, Maffesoli (em $O$ tempo das tribos) tece alguns argumentos muito significativos sobre a relevância dos encontros musicais. Enfatizando que nestas ocasióes produz-se uma sintonia por contaminação: "[...] segundo a qual os indivíduos em intenção se epifanizam em um 'nós muito fortemente presente'. É certo que a base de tudo isso é a situação face a face. Por contaminação, no entanto, é 
à totalidade da existência social que esta forma de empatia diz respeito. Além disso, quer seja pelo contato, pela percepçáo, ou pelo olhar, existe sempre algo de sensível na relação de sintonia" (MAFFESOLI, 1987, p. 103).

Curiosamente esses lugares pesquisados encontram-se entre vias de fluxo intenso, como a Rua Primeiro de Março, Av. Presidente Vargas, Rua Alfred Agache (que acessa a Av. Perimetral), Av. Rio Branco, Av. Chile, Rua Mem de Sá e Rua Riachuelo, nas quais os carros, assim como os transeuntes, circulam num ritmo frenético, num compasso mais acelerado, em que as misturas dos sons promovem um estado corporal de excesso, de esgotamento sensitivo resultando num estar tenso, firme e de pouca liberdade sensória, já que os sujeitos são tomados pelos sons, ruídos, ritmos e imagens inquietas. $\mathrm{Na}$ realidade, este ativismo musical que vem sendo estudado ocupa ruelas, praças, becos (muitas vezes - inicialmente - desvitalizados), isto é, espaços que propiciam a desaceleração e a sociabilidade.

Portanto, as interaçôes entre os sujeitos que frequentam esses encontros musicais e as arquiteturas dos lugares geram sentidos que presentificam o bem-estar e a fruição, pois nos arranjos plásticos das edificaçóes históricas a verticalidade é rompida pela horizontalidade espacial aguçando o sentido de segurança corpórea. Esse sentido de proteção para estar e viver nesses lugares reatualiza as experiências ali vividas e compartilhadas. Assim, criam-se espaços do desfrute da vida cotidiana para além dos planejamentos e programaçóes estabelecidos pelos organismos de estado ou de representantes do mercado.

Com-vivência que rompe a programação do tempo da cidade moderna destinada ao ciclo da produção-consumo-produção das mercadorias e que sublinha as diversidades vividas em seus cotidianos sócio-espaciais. A esse espaço do sentir - possibilitando a desaceleração da vida urbana, onde os sujeitos se reúnem a fim de desfrutar do encontro e das ofertas culturais disponíveis no lugar - Fernandes (2011), dialogando com Fourier e Benjamin, denominou "Ruas-Galerias". Estas seriam:

“[...] aquelas que se constituem numa organização espacial que conjuga lojas de artigos de moda, galerias de arte, cinema, livrarias, feiras livres, patrimônio arquitetônico, geralmente com calçadas largas ou ruas estreitas fechadas para circulação e ocupação dos pedestres, com a oferta de um farto serviço gastronômico. Há desse modo, a integração de diversos produtos de consumo cultural que promovem na sua grande maioria, a marca de uma forma sociocultural, de um estilo de vida, ou melhor, de estilos de vida geradores de novas sociabilidades responsáveis pelo re-desenho da espacialidade de uma cidade. Como se construissem territorialidades que se sobrepóem ao território citadino (FERNANDES, 2011, p. 275).

Em suma, como tivemos a oportunidade de analisar neste artigo, é possível - a partir deste estudo de caso - afirmar que: a música ao vivo (os afetos, estesias, interaçóes geradas nos concertos e nos encontros e rodas) e, de modo geral, os aspectos e dinâmicas culturais, quando articulados com certos perfis arquitetônicos dos lugares (como as ruas-galeria) construiriam condiçóes favoráveis para a alteração das territorialidades e do cotidiano urbano: portanto, ao 
que tudo indica, estes fatores potencializam diversas sociabilidades fundantes de um novo ethos, de novos modos de co-habitar a cidade.

\section{Referências Bibliográficas}

CANCLINI, Néstor G. Diferentes, Desiguais e Desconectados. Rio de Janeiro: Ed. UFRJ, 2005.

DE CERTEAU, Michel. A invenção do cotidiano: artes de fazer. Petrópolis: Vozes, 1994.

FERNANDES, Cíntia S. "Música e Sociabilidade: o samba choro nas ruas-galerias do centro do Rio de Janeiro". In: HERSCHMANN, Micael (org). Nas bordas e fora do mainstream musical: novas tendências da música independente no início do século XXI. São Paulo: Estação das Letras e Cores, 2011.

- Sociabilidade, Comunicação e Política. A experiência estético-comunicativa da Rede MIAC na cidade de Salvador. Rio de Janeiro: E Papers, 2009.

HAESBAERT, Rogério; MOREIRA, Ruy (orgs). Brasil século XXI por uma nova regionalização - agentes, processos e escalas. São Paulo: Max Lomonad, 2004.

HERSCHMAN, Micael. Indústria da música em transição. São Paulo: Ed. Estação das Letras e das Cores, 2010.

. Lapa: cidade da música. Rio de Janeiro: Mauad X, 2007.

IANNI, Otavio. Teorias da globalização. Rio de Janeiro: Civilização Brasileira, 2003.

MAFFESOLI, Michel. O ritmo da vida. Rio de Janeiro: Record, 2007. - Sobre o Nomadismo: vagabundagens pós-modernas, Rio de Janeiro: Record, 2001.

. O Tempo das Tribos. Rio de Janeiro: Forense-Universitária, 1987.

MARTÍN-BARBERO, Jesús. Ofício de Cartógrafo. São Paulo: Loyola, 2004.

OBICI, Giuliano. Condiçôes da escuta - mídias e territórios sonoros. Rio de Janeiro: Ed. 7 Letras, 2008.

RIO, João do. A alma encantadora das ruas. Rio de Janeiro: Garnier, 1908.

ROBERTSON, Roland. Globalização: Teoria Social e Cultura Global. Petrópolis: Vozes, 2002.

SENNETT, Richard. O declinio do homem público: as tiranias da intimidade. São Paulo: Companhia das Letras, 1987.

SODRÉ, Muniz. As estratégias sensiveis - afeto, mídia e política. Petrópolis: Vozes, 2006.

YÚDICE, George. Nuevas tecnologías, música y experiencia. Barcelona: Gedisa, 2007. 


\section{Notas}

1. Aqui aludimos ao trabalho de Richard Sennett (1987) que - nessa obra originada de pesquisas históricas sobre os espaços urbanos desde a Grécia até as cidades modernas propóe uma "nova história das cidades" através da experiência corporal.

2. Na sociedade contemporânea, para Maffesoli: “[...] ao contrário da estabilidade do tribalismo clássico, o neotribalismo se caracterizaria pela fluidez, pelos ajuntamentos pontuais e pela dispersão" (MAFFESOLI, 1987, p. 107). 